\title{
THE ROLE OF “IT” IN “ESP” LEARNING
}

\author{
Shqipe Husaj \\ Lecturer at the University "Haxhi Zeka" Peje - Kosovo \\ Shqipe.husaj@unhz.eu
}

0037744137921

\section{DOI:10.5901/mjss.2014.v5n22p280}

\section{Abstract}

This paper aims to describe the current use and the impact of different technology equipment. in language learning. The advanced information technology of the last decade has not only changed our world but has also become a part of our everyday life. Information technology as a product and as a service that no one could have imagined its impact in the past, nowadays has become a product without which life can not be lived as it is lived now. The use of some technology tools, you tube programs, video recorders etc, enable teachers to differentiate instruction and adapt classroom activities by giving learners the change to hear pronunciation directly by the English speakers, thus enhancing language learning experiences. Regardless of where we live there is a burden of human and material resources available to us to expand our languagelearning opportunities through distance learning programs and communication. IT has a great importance in assisting teachers of English language and other foreign languages as well in facilitating and mediating language learning for their students. The use of computers, mobile phones and other learning methods help learners achieve better results in schools, easier travelling and communicating. IT is saving a lot of translators time due to the google translation programs. Internet is the one that brought the world to our fingertips. Regarding internet we can share all sorts of things with the world, get authentic materials from anywhere, and interact with people in distant locations as never before. Free computer programs help learn language skills such as writing, reading, correct mistakes, translate different articles etc.

Key words; information technology, language, learners, internet, classroom etc.

\section{Introduction}

Communication is an essential part of the human experience.

The role of language in communication is to express and share ones feelings and ideas. Language allows us to express what we think and feel to another group of people. It enables us to learn, teach, express our preferences, agree on certain norms and standards within a society in order for us to co-exist. Language is instinctive even in cavemen who expressed themselves by sound, body language and even simple drawings.

English is such an important language because it is spoken by millions of people world-wide. Its prominence makes it a good choice for multinational businesses that need an international language with which to communicate. Fluency of language allows businesses to bridge an increasingly diverse workforce with a single language. This single-language model encourages much greater efficiency in communication. English is important since it is a well known language and has frequently been referred to as a world language.

\section{English for specific purposes (ESP)}

Learning a language is something we're born to do. As children, we learn to think, learn to communicate and understand grammar rules in our mother tongue, or native language. From then on, we learn all new languages in relation to the one we first knew - the one that we used to understand the world around us for the first time ever. English for specific purposes (ESP) is a needs based concept to determine which language skills should be profitably developed for professional success of students. Learning English as a foreign language (EFL) or general English indicates the use of English in a non - English speaking region. Nowadays it is widely accepted that learning to speak English in general may be the best thing one can do to improve everyday life. How can one have access to information that other people can not get, how to travel without being accompanied by a translator, and the most important of all, how to leave the others miles behind us? The answer is; simply by learning general English. But it is even more important for the learners of English to be able to learn English for all sorts of transactions, as the learners of ESP already have the basics of the English language and are learning the language in order to communicate a set of professional skills and to perform particular job related functions. (Singh: 2005). 
When teaching ESP there are certain basic questions to be taken into account such as: who the learners are, what their view towards language learning is, what particular skill will they be needing in their account, on the job situation, what their linguistic background or level of competence is, what their purpose and expectations are, and smilar .

Rosenberg (in Netiksiene: 2006) has written an article in which she has analyzed the differences between English for specific purposes and general English. In her article she considers where English for Specific Purposes, respectively Business English and General English overlap. To address these questions specifically, the author of the article has conducted a survey. She has asked a group of University teachers of the English language to brainstorm the differences and the similarities between general English and Business English. A number of ideas suggested by the participants in the brainstorming activity are listed below:

Business English

Specialized vocabulary

Motivation related to job

Teach negotiation and presentation

Techniques

Students very goal-oriented

More serious

Business correspondence

\section{General English}

Free time activity

More freedom in deviation from plan

More time for games

Literature

Songs

More relaxed atmosphere

General writing skills

According to Rosenberg, when the two lists are analyzed it may be concluded that general English and English for Specific Purposes have in common the following: Grammar and functions - grammar rules are the same everywhere; general vocabulary, and anxiety about capabilities, everyday English, small talk, travel vocabulary, survival English, and current events. ESP (English for Specific Purposes) according to Dudley - Evans (in Anthony: 1997) has been referred to as "applied ELT" (English Language Teaching) as the content and aims of any course are determined by the needs of a specific group of learners. ESP is often divided into EAP (English for Academic Purposes) preparing students for academic studies in universities around the world. Students learn skills such as writing academic papers, taking lecture notes and studying for exams, and EOP (English for Occupational Purposes) teaching English in general or particular workplace training and development. Further sub-divisions of English for Occupational Purposes are sometimes made into business English, professional English (e.g. English for doctors, lawyers) and vocational English (e.g. English for tourism, nursing, aviation, and bricklaying). The characteristics of ESP summarized by Dudley - Evans are as follows:

ESP is designed to meet the specific needs of the learners, ESP makes use of the underlying methodology and activities of the specialism it serves, therefore it is centered not only on the language (grammar, lexis, register), but also the skills, discourses and genres appropriate to those activities. Nowadays ESP practitioners are also becoming increasingly involved in intercultural communication and the development of intercultural competence (Gatehouse).

Traditionally ESP courses were typically designed for intermediate or advanced adult learners. Nowadays many students can start to learn academic or vocational English at an earlier age and at a lower level of proficiency. ESP concentrates more on language in context than on teaching grammar and language structures. It covers subject varying from accounting or computer to tourism and business. Therefore the defining characteristic of ESP according to Dudley-Evans (Gatehouse) is that teaching and materials are based on the results of a needs analysis. Consequently the key questions are:

What do students need to do with English?

Which of the skills do they need to master and how well?

Which genres do they need to master either for comprehension or production purposes?

English for Specific Purposes has become increasingly important as there has been an increase in vocational training and learning throughout the world. With the spread of globalization has come the increasing use of English as the language of international communication. More and more people are using English in a growing number of occupational contexts. Students are starting to learn and therefore master general English at a younger age and so move on to ESP at an earlier age. 
In some English speaking countries for instance Great Britain, Canada, America etc. governments are launching initiatives to help economic migrants obtain the practical English skills necessary to function in the workplace. For example, the new English to Speakers of Other Languages (ESOL) for Work Qualifications in the United Kingdom are designed to help employers and employees access courses which offer them the functional language skills demanded across a variety of employment sectors. Content includes topics such as customer care and health and safety (Dudley-Evans, 2001 in British Council). Kiktauskiene (2006) states that teaching language for specific purposes is determined by different professional/occupational, social and other - needs of the learner. Therefore, English for specific purposes (ESP) includes specialized programmes which are designed to develop the communicative use of English in a specialized field of science, work or technology. To be able to speak on a professional subject is not enough to know general vocabulary.

Technology and ESP learning

As humanity evolves, technology is evolving with it too, and impacting the way the communicative aspect of our lives functions. The effects of modern technology on how we communicate with one another are vast and varied, with both negative and positive impacts for our business and personal lives. Learning a second language whatever it may be especially the language that adults have as the language of their profession called language for specific purposes ( ESP), both pronunciation and writing in last decades based on some studies resulted that some adult learners scored as well as native speakers. All this because of having the newest technology at home, starting from mobile Phone, iPad, computer etc. Modern technology is drastically altering the speed at which we communicate. An email is delivered in a matter of minutes. Text messaging allows us to send short messages to each other's phones in seconds. We can reach anyone by telephone almost anywhere with the continued development of network coverage. Instant messaging and video conferencing allow groups of people to speak in real time from all over the country and

world The fact that learning a little every day by using one of these equipments is actually more effective than learning for hours at a time, can be proved by the fact that children have their favorite programs on their tablets, iPads, TV etc all day long even when going to sleep, while adults repeating almost same and new things everyday on mobile phone by using different language programs to express themselves, when chatting to the others or when wanting to write an academic letter or application, by having possibility of finding a sample of it on the internet just by google searching and the next time another sample. Social networking sites, such as "facebook", "skype" and "tweeter", are making information quicker, shortening forms of full words, and fully developing sentences and thought. This major social trend in the use of technology has a tremendous positive effect on education, especially for English language learners. These social networks facilitate the learner being able to meet friends who speak the language they are learning. Within this format they can tweet to new friends, make comments on their tweets and postings and also chat with them. So it is much easier to keep things in mind by seeing, reading or hearing them more often. In networks one can meet native and non native people online and have an interesting conversation with them in either groups or individuals by a call system. In this way everyone will learn the customs and traditions of the others nationalities and countries. In a short period of time they will learn new words, and different forms and structures from each other. In this way you are more comfortable with any mistakes in speech and the advantage of native speakers who are well versed in their language offering you correction. An interview transmitted on a TV channel showed that one in a five adults prefer to stay hungry rather than without a mobile phone, they are ready not to watch a TV but have a mobile phone, which means their life is totally addicted to mobile phones and internet. A large number of respondents have declared that they wake up at night just to see if there is any news on their phones, and the first thing they do in the morning is open their social networks and chat with their friend from different places. When asked of the advantages of these activities all of them have answered clearly that apart from being socialized they learn foreign languages. Most of their time is spent listening to MP3 player, reading lessons from LingQ on IPad, or iPhone, during the day. Respondents have also added that they don't necessary need to go to a classroom, or to a language lab to learn English, don't necessary need to spend a lot of money on language courses any more.

\section{Classroom and technology}

In recent years we have witnessed a significant advances in technology, which have changed our world and have also become a part of our every day life. Technology is something that can not be viewed as our optional resource or something that can be dispensed with but, it is a reality which to an increasing extend together with the science dictate our language in which we thing and speak, because we either speak that language or remain mute. English for specific purpose (ESP) like any other aspect of our lives, has also been transformed by technology, especially by the use of computers in our classroom tasks as teachers and researchers. The role of the teacher is to coordinate the context surrounding language learning in order for students to succeed in improving their language skills (Day \& Lloyd, 2007). New technologies are 
becoming essential to the learning of a second language in general especially language for specific purposes. Therefore, a fundamental issue that needs to be resolved is how to integrate these new technologies into the classroom setting. The resolution of this issue is largely the role of the teacher as an educator and one who guides the learning process. Multimedia teachings enrich teaching content and make the best of class time and break the "teacher- centered" teaching pattern and fundamentally improve class efficiency towards "student-centered". Due to large classes it is difficult for the students to have speaking communication. The utilization of multi-media sound lab materializes the individualized and co-operative teaching. The traditional teaching model mainly emphasized on teachers' instruction, and the information provided is limited due to traditional classes. On the contrary, multimedia technology goes beyond time and space, creates more vivid, visual, authentic environment for English learning, it stimulates students' initiatives and economizes class time meanwhile increases class information. This way the role of computers in language instructions has become an important issue all around the world. The computer can play a useful part in the language class only if the teacher first asks: What is it that I want my students to learn today, and what is the best way for them to learn it? In most cases, the answer will probably not involve the computer, but there will be occasions when the computer is the most suitable and, for the students, most enjoyable way to get the job done. In addition, computer teaching is also flexible. It is obvious that the context can be created not only in the classroom, but after class too. Multimedia language teaching can also create a multimedia language environment for the purpose of conducting language teaching. English teaching itself must focus on the guidance of teachers and be student -centered ( Holec, 1981), which is one of the principles for language teaching, because students are bound to have some problems in classroom teaching, which can be addressed under the guidance of teachers. In such circumstances, students can use the new technology to their advantage, such as manipulating the network to contact teachers, and receiving answers by email. It is rare to find a language class that does not use some form of technology/ computer. In recent years computers are used to both assist and enhance language learning. Teachers at different levels incorporate various forms of technology to support their teaching, engage students in learning process, provide authentic examples of the target culture, and connect their classrooms in a certain country in other countries where the target language is spoken.

It is helpful to think of the computer as having the following main roles in the language classroom:

teacher - the computer teaches students new language

tester - the computer tests students on language already learned

tool - the computer assists students to do certain tasks

data source - the computer provides students with the information they need to perform a particular task

communication facilitator - the computer allows students to communicate with others in different locations

Further, some technology tools enable teachers to differentiate instruction and adapt classroom activities and homework assignment, thus enhancing the language learning experience. Distance learning programs can enable language educators to expand language-learning opportunities to all students, regardless of where they live, the human and material resources available to them, or their language background and needs. In sum, technology continues to grow in importance as a tool to assit teachers of foreign languages in facilitating and mediating language learning for their students.

\section{Computer effectiveness in classrooms}

While technology can play an important role in supporting and enhancing language learning, the effectiveness of any technological tool depends on the knowledge and expertise of the qualified language teacher who manages and facilitates the language learning environment. In some cases however, school and university administrators have permitted technology to drive the language curriculum and have even used it to replace certified language teachers.

The use of computers in language learning is a well-researched field, with studies on different computer applications and their pedagogical value to language learning. In order for a learner to achieve the four skills: writing, reading, listening and speaking, during language learning it has to play an active role. In a computer based language learning environment the computer "will act as an aid to the learning process, facilitate learning to the provision of learning materials and resources and enable interactions between all learners and teachers involved in the environment." (Barr. P. 29) According to some existing literature the effectiveness of technology used in language education is very limited in four aspects: a) The number of systematic, well designed empirical evaluative studies of the effects of technology uses in language learning is very small, b) the settings of instruction where the studies were conducted were limited to higher education and adult learners, c) the languages studied were limited to common foreign languages and English as a foreign or second language, and d) 
the experiments were often short-term and about one or two aspects of language learning (e.g., vocabulary or grammar). However the limited number of available studies shows a pattern of positive effects. They found that technology-supported language learning is at least as effective as human teachers, if not more so. Technology is an ill-defined concept that encompasses a wide range of tools, artifacts, and practices, from multimedia computers to the Internet, from videotapes to online chat rooms, from web pages to interactive audio conferencing. These technologies vary a great deal in their capacity, interface, and accessibility. It is thus misleading to think the effects of videotapes are the same as those of the online chat rooms just because they are all called "technology." Second, the effects of any technology on learning outcomes lie in its uses. A specific technology may hold great educational potential, but, until it is used properly, it may not have any positive impact at all on learning. Thus, assessing the effectiveness of a technology is in reality assessing the effectiveness of its uses rather than the technology itself. Since most information and communication technologies (ICT) can be used in a variety of ways, some more effective than others, it is inappropriate to over generalize the effectiveness of one way of using the technology to the technology itself. Third, to further complicate things, the effectiveness of an educational approach is highly mediated by many other variables-the learner, the task, the instructional setting, and of course the assessment tool. Thus, even the same use of a particular technology in different instructional settings may result in different learning outcomes.

The effectiveness of technology on language learning is dependent on how it is used. Certain technologies are more suitable than others for certain learning tasks for certain learners. Therefore research about appropriate ways and contexts of technology use is much needed (Salaberry, 2001).

The benefits of adding a computer component to language instruction include

(1) multimodal practice with feedback

(2) individualization in a large class

(3) pair and small group work on projects, either collaboratively or competitively

(4) the fun factor

(5) variety in the resources available and learning styles used

(6) exploratory learning with large amounts of language data

(7) real-life skill-building in computer use

Programs available for language learning

There are still a great many grammar and vocabulary drill programs available, but at least the vocabulary ones have started to be contextualized and to incorporate graphics, audio recording and playback, and video. Drills do have a place in language learning, particularly in the first stages of vocabulary acquisition where giving the same information in multiple modes, such as visual plus aural plus textual, enhances recognition and recall. More sophisticated error-checking can provide students real help in the feedback they receive, directing them to further practice or moving them to the next stage. Those who do need extra help with those aspects of language that improve with practice can use small, focused programs to give them additional time and assistance outside of regular class time.

Pronunciation work in particular has benefited from technology. Most pronunciation programs now incorporate some sort of voice recording and playback to let students compare their recording with a model. (Warschauer, M., \& Healey, D. (1998)). Many of the English pronunciation programs, such as Ellis Master Pronunciation from CALI, American Accent Program from Ford Language Institute etc, have video clips and animations of the mouth making specific sounds. Some vocabulary programs, such as Practice Makes Perfect and Vocabulary Builder from The Learning Company, See It, Hear It, Say It! from Courseware Publishing International, use speech recognition technology to help students see how close they've come to the target pronunciation in several languages. A few programs, such as SpeechViewer from IBM and VideoVoice from MicroVideo, let students try to make the graphical representations of their speech overlap a teacherrecorded template. These visual cues work in conjunction with aural cues to provide sophisticated feedback.

Most drills now include games, as well, using the power of the computer and competition for or a collaboration toward a goal--the fun factor--to motivate language learning. Notable among the drill-as-game are Blackbelt Japanese from Educorp; English, French, Spanish, and German versions of Hangman (Hangman, La Guillotine, La Corrida de Toros, and Apfelschuss) from Gessler; Matchmaster from Wida; and Word Attack! from Davidson. These programs provide a varying amount of instruction along with the games, but all expect the teacher to do most of the work in introducing the concepts that students will practice. 
Technology verses teacher

Although much of what is done at the computer can be done in other ways, some activities are far more productive with the resources that the computer can bring to bear. Text reconstruction is a good example. A teacher can create a sentence jumble by cutting up pieces of paper, but programs such as NewReader from Hyperbole can do it painlessly. With a paper cloze, students who get stuck on a word have to give up completely and look at the whole text (or ask the teacher individually for a specific answer); on the computer, they can get a letter or word as a hint and go on. Both NewReader from Hyperbole and Text Tanglers from Research Design Associates can create a variety of text reconstruction activities for a plain-text word-processed document, greatly expanding any classroom reading that the teacher has prepared. Crossword and word search puzzles are examples of activities that take a great deal of time to prepare by hand, but very little time to do on the computer. The teacher types in a series of words, and the machine formats them appropriately. With a crossword puzzle, the teacher is then prompted for each clue, and the machine formats the whole crossword with clues on the page to be worked on the computer or printed out. Because the process is easy, students can create crosswords for each other. A program like Crossword Creator from Centron adds a thesaurus, making it even easier for students and teachers to formulate clues.

The writing process is another area where computers have added a great deal of value. Some programs, such as IdeaFisher from IdeaFisher Systems and Inspiration from Inspiration Software, help students in the pre-writing stage to generate and outline ideas. Most word-processors now come with spelling checkers, giving weak spellers some help in finding their errors and recognizing the correct spelling from a list of options.

Dictionaries, both translating ones have sound and video clips to help learners recognize a word when it's spoken and put it into context. The Computer Screen can't Substitute the Blackboard Some teachers use the computer screen as the blackboard, They have input exercises, questions, answers and teaching plans into the computer and display them piece by piece, without taking down anything on the blackboard or even the title of a lesson. It is known that teachers are supposed to simulate situations based on teaching and guide the students to communicate in English. Beside traditional writing on blackboard is concise and teachers can make adjustment and amendment to it if necessary. Furthermore, experienced teachers know well that a perfect courseware is an ideal project in mind, and that in practice, they need to enrich the content on the blackboard with emerging of new question raised by the students.

Some teachers may possess the improper concept that they would totally apply multimedia technology in their teaching. It is also believed that the more utilization of multimedia technology, the better class atmosphere may grow, the more actively the students get involved in class participation, the more easily the material access to the students. Apparently, the students show some interest in leaning, but actually, they feel like looking on. In practice, the more unconscious attention the students pay, the more interference of teaching information during transmission, the less the students take from the language materials. It is impossible to effectively train the students' language expression in class time. It is clear that in spite of advantages of application of technology, it assists in teaching. During practical teaching, it is part of a complete teaching procedure. In practice, if multimedia technology would be properly implemented in English teaching, the students could make full use of English speaking and listening materials and develop their overall capacities, which is the objective for us to introduce multimedia technology to modern teaching thus, this leads to systematic training on students' listening, speaking, reading and writing, makes teachers' instructions come into great play, help the student gain basic knowledge as well as language training at classes, improves their expression ability in English and lays a fundamental basis for their English communication.

\section{Conclusion T}

Everyone learns a foreign language using a range of methods they find best. In this modern era we have a range of new technologies at our disposal that can help learners in the language learning process so why not use them to their full potential, but never forget the role of the teacher in classrooms. We believe that in future, the use of technology in English teaching and learning will be further developed, and hopefully focused more on student-centered but less time-consuming. In conclusion it should be added that one more technology opens a new window to the world.

\section{References}

- Dudley-Evans, T.(2001). English for Specific Purposes. In the Cambridge guide to TESOL, Cambridge University Press. Available at www.britishcouncil.com 
-Hinkel, E. (2005)-Handbook of research in second language teaching and learning. Available at www.indiana.edu/1630tesp • Cavanaugh, C. S. (2001).

Cavanaugh, C. S. (2001). The effectiveness of interactive distance education technologies

in K-12 learning: A meta-analysis. International Journal of Educational

Telecommunications, 7 (1), 73-88.

-Chao, C.-C. (1999). Theory and research: New emphases of assessment in the language

learning classroom. In E. Hanson-Smith (Ed.), CALL Environments: Research,

practice, and critical issues (pp. 243-256). Alexandria, VA: TESOL.

The effectiveness of interactive distance education technologies

in K-12 learning: A meta-analysis. International Journal of Educational

Telecommunications, 7 (1), 73-88.

England, J., Hutchings, P. and McKeanchie, W. J. The Professional Evaluation of Teaching. Available at http://www.acls.org

Day, D. \& Lloyd, M. (2007). Affordances of online technologies: More than the properties of the technology. Australian Educational Computing, 22(2), 17-21.

Fiorito, L. (2005) Teaching English for Specific Purposes (ESP). Available at http://www.usingenglish.com/teachers/articles/teaching-english-for-specific-purposes-esp.html

Geffner, A. B. (2004). Business English and Economics .Available at http://www.amazona.ca

Harding, K (2007). English for Specific Purposes, Oxford University Press

Warschauer, M., \& Healey, D. (1998). Computers and language learning: An overview. Language Teaching, 31, 57-71.

http://www.ehow.com/about 6455160 effect-modern-technology-communication-processes.html

Zhanghongling ( The development tendency of the modern foreign language teaching and the computer assisted instruction. Computer- Assisted Foreign Language Education 3.155 